\title{
əThe Influence of South Pacific Convergence Zone Heating on the South Pacific Subtropical Anticyclone $\mathscr{O}$
}

\author{
Abdullah A. Fahad, ${ }^{a}$ Natalie J. Burls, ${ }^{a}$ Erik T. Swenson, ${ }^{\mathrm{b}}$ And David M. Straus ${ }^{\mathrm{a}}$ \\ ${ }^{a}$ Department of Atmospheric, Oceanic, and Earth Sciences, George Mason University, Fairfax, Virginia \\ ${ }^{\mathrm{b}}$ Center for Ocean-Land-Atmosphere Studies, George Mason University, Fairfax, Virginia
}

(Manuscript received 9 July 2020, in final form 26 January 2021)

\begin{abstract}
Subtropical anticyclones and midlatitude storm tracks are key components of the large-scale atmospheric circulation. Focusing on the Southern Hemisphere, the seasonality of the three dominant subtropical anticyclones, situated over the South Pacific, South Atlantic, and south Indian Ocean basins, has a large influence on local weather and climate within South America, southern Africa, and Australia, respectively. Generally speaking, sea level pressure within the Southern Hemisphere subtropics reaches its seasonal maximum during the winter season when the Southern Hemisphere Hadley cell is at its strongest. One exception to this is the seasonal evolution of the South Pacific subtropical anticyclone. While winter maxima are seen in the South Atlantic and south Indian subtropical anticyclones, the South Pacific subtropical anticyclone reaches its seasonal maximum during local spring with elevated values extending into summer. In this study, we investigate the hypothesis that the strength of the austral summer South Pacific subtropical anticyclone is largely due to heating over the South Pacific convergence zone. Using added-cooling and added-heating atmospheric general circulation model experiments to artificially change the strength of austral summer diabatic heating over the South Pacific convergence zone, our results show that increased heating, through increased upper-level divergence, triggers a Rossby wave train that extends into the Southern Hemisphere midlatitudes. This propagating Rossby wave train creates a high and low sea level pressure pattern that projects onto the center of the South Pacific subtropical anticyclone to intensify its area and strength.

KEYWORDS: Anticyclones; Atmosphere-ocean interaction; Atmospheric circulation; Baroclinic flows; Cyclogenesis/ cyclolysis; Rossby waves
\end{abstract}

\section{Introduction}

Subtropical anticyclones (SAs) and the storm tracks are salient elements of the large-scale atmospheric circulation within both hemispheres. SAs are semi-permanent high pressure systems situated over each subtropical ocean basin that both influence and respond to sea surface temperature (SST), precipitation, atmospheric moisture transport, and wind-driven ocean circulation. In the Southern Hemisphere, the South Pacific SA (SPSA), South Atlantic SA (SASA), and south Indian SA (SISA) dominate regional precipitation variability on subseasonal to decadal time scales over South America (Doyle and Barros 2002; Reboita et al. 2010), southern Africa (Burls et al. 2019), and Australia (Sturman and Tapper 1996).

In the zonal mean, SAs are primarily associated with the descending motion of the Hadley cell that creates a high pressure belt over the subtropical region in both hemispheres. However, the SAs themselves are locally more intense than the rest of the subtropical high pressure belt. Bergeron (1930) was the first to make the distinction between the uniform

๑ Denotes content that is immediately available upon publication as open access.

Supplemental information related to this paper is available at the Journals Online website: https://doi.org/10.1175/JCLI-D-200509.s1.

Corresponding author: Abdullah A. Fahad, afahad@gmu.edu subtropical high pressure belt and the subtropical high pressure systems over the subtropical oceans within the context of airmass and frontal development. The Hadley circulation is strongest in the winter hemisphere due to the enhanced meridional temperature gradient from the warm tropics to the cold winter hemisphere, and one might therefore expect the SAs to reach their seasonal maxima in local winter (Hoskins 1996; Lee et al. 2013). This expectation is however only true for the SASA and the SISA. The SAs in the NH reach their climatological maximum in both area and strength during local summer (Hoskins 1996; Rodwell and Hoskins 2001; Seager et al. 2003; Nigam and Chan 2009), as does the topic of this study, the SPSA. This phenomenon whereby certain SAs reach their seasonal maximum in local summer raises the question of what else controls the area and strength of SAs.

Several studies have shown that the seasonal evolution in the strength of SAs is associated not only with the strength of Hadley cell descent but also with local monsoonal heating over the surrounding continents. Hadley cell descent dominates the zonal mean component of SAs, whereas the surrounding subtropical landmass heating dominates the zonally asymmetric component. The importance of surrounding land monsoonal heating was first recognized by Ting (1994). Using a steadystate, linear, primitive equation model Ting (1994) analyzed the large-scale circulation due to local monsoonal heating, especially focusing on the Indian summer monsoon heating. Later, Hoskins (1996) argued that heating over the continents to the east of an ocean basin largely contributes to the summer intensification of its SA, which explains the North Pacific SAs maximum strength during local summer, June-August (JJA), 
when the local Hadley cell descent is weak. The continental heating to the east of the ocean basin releases latent heat during the summer and generates a Rossby wave response to the northwest of the heated continent. The warm air from this monsoonal heating descends over the eastern flank of the adjacent ocean basin. Rodwell and Hoskins (2001) and Chen et al. (2001) later went on to demonstrate that heating on both continents surrounding an ocean basin contributes to the formation of SAs. Rodwell and Hoskins (2001) suggested that the equatorward portion of the SA forms as a Kelvin wave response to the monsoonal heating over the continent to the west of the ocean basin. For the SH, Rodwell and Hoskins (2001) argued that the orography of the SH continents plays a significant role in positioning SAs.

Wu and Liu (2003) and Liu et al. (2004) highlight that it is essentially diabatic heating differences between land and ocean that control the development of summer SAs. A quadrupole heating pattern of heating over the land and cooling over the eastern flank of subtropical oceans during local summer acts as a driver for the atmospheric circulation and the development of SAs (Wu and Liu 2003). In general, total diabatic heating differences act to cool the eastern flank of the ocean basins and warm the continents. The eastern flank of the subtropical ocean regions is dominated by longwave cooling, the western flank of the subtropical ocean regions is dominated by a combination of longwave cooling and latent heating, the western flanks of the continents are dominated by sensible heating, and the eastern flanks of the continents are dominated by latent heating. This heating pattern gives rise to anticyclonic upper-troposphere circulation over the land, and cyclonic upper-troposphere circulation over the neighboring oceanic region, with cyclonic surface circulation over land and an anticyclonic surface circulation over the ocean. $\mathrm{Wu}$ and Liu (2003) proposed that this distinct circulation pattern exists as a response to the quadrupole heating. Seager et al. (2003) also argued that zonal asymmetries in SSTs can act as a secondary forcing in subtropical ocean basins and influence the seasonal strengthening of SAs.

The NH SAs reach their maximum strength during local summer (JJA) due to Asian, North African, and North American summer monsoon heating contributing to the asymmetric component of the NH SAs despite the fact that the local Hadley cell descent is weak in this season (Hoskins 1996; Rodwell and Hoskins 2001; Nigam and Chan 2009; Chen et al. 2001). In the $\mathrm{SH}$, local summer monsoonal heating is not as strong as that in the NH due to the smaller landmass-to-ocean ratio. As a result, the SH SASA and SISA reach their maximum during local winter (JJA) due to stronger Hadley cell descent during local winter, rather than local summer (Richter et al. 2008; Nigam and Chan 2009; Richter et al. 2010; Sun et al. 2017; Vizy and Cook 2016). Interestingly, this is not the case for the SPSA. As shown in Fig. 1, climatologically the SPSA is stronger during local summer, December-February (DJF), compared to local winter (JJA), whereas the seasonal cycles of the SASA and the SISA peak in area and strength during local winter (JJA). The SPSA's seasonal cycle in area and strength reaches its maximum during September-November (SON), but remains intensified until February (Lee et al. 2013) (Fig. 1 and Fig. S1 in the online supplemental material). This distinct climatological feature of the SPSA is consistently present in the ERA-Interim dataset (Figs. 1a,b), the Modern-Era Retrospective Analysis for Research and Applications, version 2 (MERRA-2) (Figs. 1c,d), the Hadley Centre Sea Level Pressure (HadSLP2) (Figs. 1e,f), the Community Earth System Model (CESM2) CAM6 (Figs. 1i,j), and the multimodel mean of the historical and future simulations from phases 5 and 6 of the Coupled Model Intercomparison Project (CMIP5 and CMIP6) (Fahad et al. 2020).

The deviation of zonal mean climatological SLP (climatological SLP - zonal mean climatological SLP) shows that the SPSA has a stronger asymmetric component during DJF than JJA, and a stronger asymmetric component compared to the other two SH SAs during DJF (Fig. S2). In fact, the asymmetric SLP component of the SPSA is almost nonexistent in JJA (Fig. S2). Using the Community Atmospheric Model, Lee et al. (2013) show that this phenomenon exists in CAM. Lee et al. (2013) modified the seasonal cycle of NH top of the atmosphere insolation, SSTs, and sea ice cover by shifting it by 6 months to make the $\mathrm{NH}$ seasons occur in the same months as the equivalent season in the SH. They find that without the JJA interhemispheric energy transfer associated with the $\mathrm{NH}$ summer monsoons the SPSA only exists as a subtropical high pressure system during DJF, while the SISA and the SASA still reach a maximum in area and strength during JJA in the same experiment (other seasons not shown). Lee et al. (2013) also identified heating and cooling regions near the northern part of the tropics at $500 \mathrm{hPa}$, and show how this tropical heating influences SAs in both hemispheres during JJA. Using a steadystate, linear primitive equation model that solves the sigmacoordinate equations linearized about a zonally symmetric basic state, Nigam and Chan (2009) show that adding heating over the tropical Pacific acts as a forcing on the North Pacific SA's seasonal development from winter to summer. They show that tropical heating over the intertropical convergence zone (ITCZ) and South Pacific convergence zone (SPCZ) has a large influence on the midlatitude atmospheric circulation and the seasonal evolution of the North Pacific SA. In future climate models projection, Song et al. $(2018 \mathrm{a}, \mathrm{b})$ found that a seasonal delay in the evolution of tropical rainfall over the ITCZ and SPCZ region can influence both the $\mathrm{NH}$ and $\mathrm{SH}$ by weakening the $\mathrm{NH}$ and strengthening SH SA during JJA compared to March-May (MAM). The influence of SPCZ heating on the climatological strength of the SH SAs has however remained largely uninvestigated.

The SPCZ is a unique feature over the southwestern Pacific Ocean with a spatial pattern of precipitation that reaches a maximum in strength during DJF (austral summer) and a minimum during JJA (austral winter) as a result of the seasonal cycle of solar heating. The vertically integrated diabatic heating associated with the SPCZ also has similar seasonality (Figs. 2c,d). The diabatic heating over the SPCZ region is maximum during DJF and shifts to its most southern position. The divergence of horizontal winds at $200 \mathrm{hPa}$ also shifts southward along with the SPCZ heating region (Figs. 2e,f). A Rossby wave tracing initialized from the SPCZ region using ERA-Interim climatology (1979-2016) for zonal wavenumber $k=5$ shows that the density of the Rossby wave ray travels 

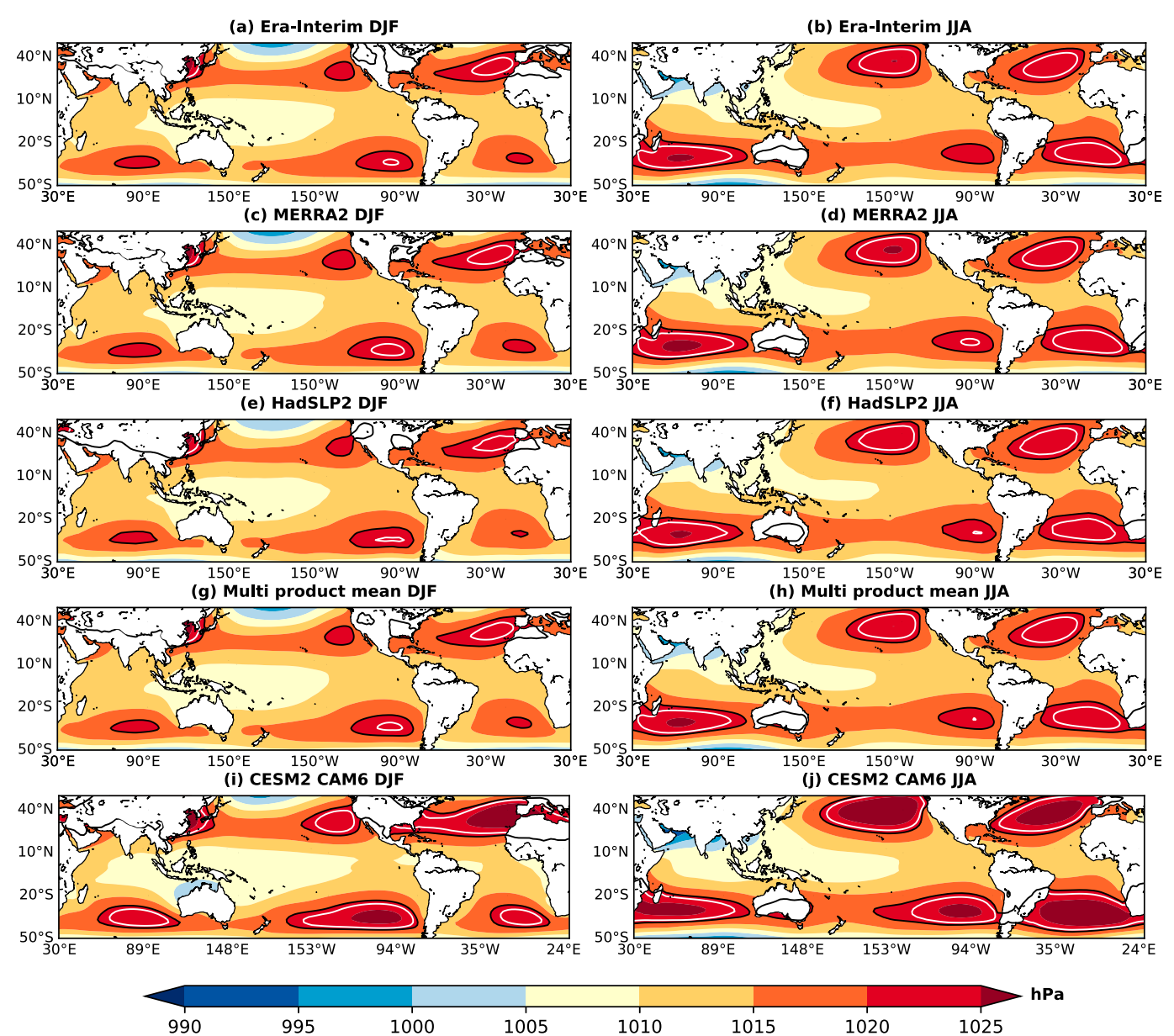

FIG. 1. SLP climatology (unit: hPa) for (left) DJF and (right) JJA. The SLP climatology for both seasons is computed from (a),(b) ERA-Interim (1979-2016), (c),(d) MERRA-2 (1980-2016), (e),(f) HadSLP2 (1980-2016), (g),(h) the multiproduct mean (average of ERA-Interim, MERRA-2, and HadSLP2), and (i),(j) CESM2 CAM6 (30-yr climatology). The 1020 -hPa contour is in black and the 1022-hPa contour in white.

mostly over the subtropical region during DJF, especially over the center of the SPSA. A similar result is seen with other stationary wavenumbers $(k=4,6$; results not shown). In contrast, Rossby wave rays are less dense during JJA and travel over the equatorward flank of SH SAs (Figs. $2 \mathrm{~g}, \mathrm{~h}$ ).

The interannual variability of the SPCZ is closely linked to tropical Pacific SST and El Niño-Southern Oscillation (ENSO) (Trenberth 1976; Folland et al. 2002; Lintner and Boos 2019; Brown et al. 2020), as well as the Madden-Julian oscillation (MJO) (Matthews 2012). During austral summer (DJF), the SPCZ shifts toward the equator as a result of El Niño events. In contrast, SPCZ shifts toward the pole during La Niña events during DJF (Linter and Boos 2019). Several studies have shown how tropical forcing related to SPCZ heating influences the $\mathrm{SH}$ extratropics through a remote teleconnection. Using NCEP-NCAR reanalysis data, Renwick and Revell (1999) showed that atmospheric blocking over the southeast Pacific Ocean is remotely forced by anomalous convection in the tropics. Renwick and Revell (1999) show divergence associated with the anomalous convective region (e.g., ITCZ and SPCZ), defined by anomalous outgoing longwave radiation, forces linear Rossby wave propagation that results in increases in atmospheric blocking over the South Pacific region. Taschetto et al. (2010) find that convective activity over the SPCZ region during austral summer months (DJF) can be amplified by ENSO Modoki events, when SST is warmer over the central tropical Pacific. This amplified SPCZ heating can create a cyclonic circulation, the convergence of moisture, and enhanced precipitation through remote Rossby wave propagation. Clem and Renwick (2015) also show similar results that strong SPCZ shifts toward the SH pole contribute significantly to the variability of early austral spring atmospheric circulation and surface temperature trends over the South Pacific and Atlantic region.

The purpose of this paper is to use perturbed diabatic heating GCM experiments to determine the extent to which the heating over the SPCZ influences the large-scale circulation of the SH, specifically as the mechanism leading the SPSA to reach its maximum in area and strength during DJF. Increased SPCZ heating changes the upper-level divergence 

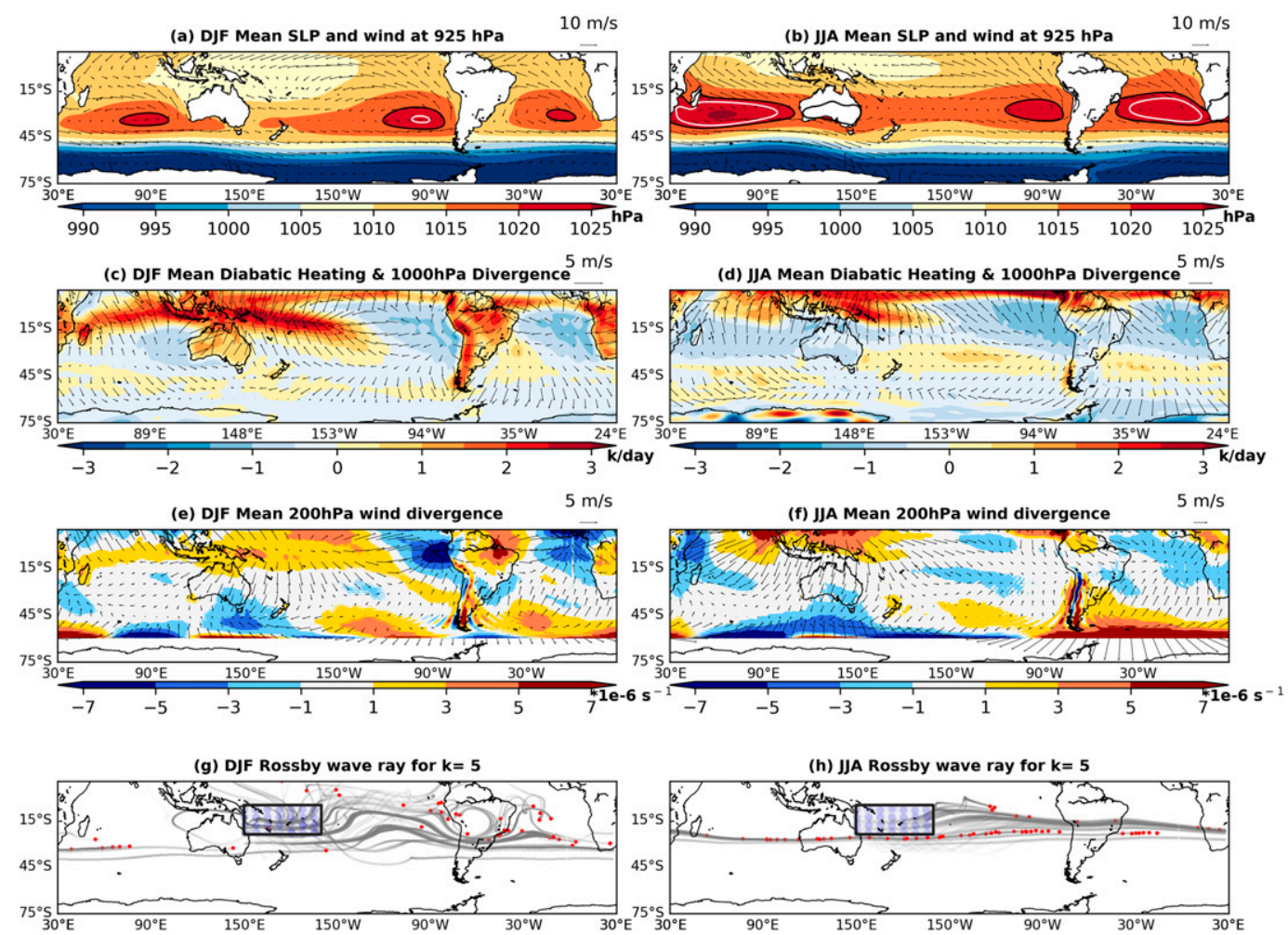

FIG. 2. ERA-Interim (1979-2016) climatology of (a) DJF and (b) JJA SLP (shaded; unit: hPa), and 925-hPa wind. The $1020-\mathrm{hPa}$ contoure is in black and the $1022-\mathrm{hPa}$ contour in white. The $1022-\mathrm{hPa}$ contour is only present in the SPSA during DJF, and the SISA and SASA during JJA. Also shown is ERA-Interim (1979-2016) climatology of (c) DJF and (d) JJA vertical-mean diabatic heating (shaded; unit: $\mathrm{K} \mathrm{day}^{-1}$ ), and the 1000-hPa divergent wind component (vectors), as well as ERA-Interim (1979-2016) climatology of (e) DJF and (f) JJA mean of 200-hPa divergence (unit: $\mathrm{s}^{-1}$ ). The wind component of divergence is plotted as vectors (unit: $\mathrm{m} \mathrm{s}^{-1}$ ). The magnitude of divergence is scaled by $10^{-6}$. The Rossby wave ray traced from the SPCZ location is shown for stationary zonal wavenumber $k=5$ for (g) DJF and (h) JJA. The Rossby wave paths are shown as gray lines, with the initial location as blue circles, and the end of the ray as red dots.

and divergent wind (advecting vorticity), which can act as a forcing to trigger a Rossby wave, significantly perturbing the balance of vorticity (Holton and Hakim 2012). We hypothesize that the resultant Rossby wave train propagates into the extratropics, impacting surface pressure. The specific hypothesis to be tested is that during DJF, the changes forced by the SPCZ can directly project onto the SPSA, affecting its area and strength.

The midlatitude storm tracks largely influence Earth's heat and momentum budget. We further investigate how heating over the SPCZ region can influence the SH storm tracks, as the transient heat and momentum fluxes and local diabatic heating associated with storm tracks act to indirectly amplify the forced response from tropical forcing (Held et al. 1989). So, it is important to understand how SH storm tracks respond to changes in the heating over the SPCZ.

The study is structured as follows: a description of the methods and data used in this study is presented in section 2; the results from reanalysis data and our numerical climate model experiments are presented in section 3; and last, section 4 provides a summary and conclusions drawn from the analysis.

\section{Methodology}

The observationally based data (years 1979-2016) used in this study are from the ERA-Interim product (Dee et al. 2011), MERRA-2 (Gelaro et al. 2017), and HadSLP2 (Allan and Ansell 2006). Atmospheric diabatic heating is estimated from ERA-Interim data (following Swenson et al. 2019) and is computed from four times daily circulation and thermodynamic fields at the full horizontal resolution $(512 \times 256$ Gaussian grid) and at 37 pressure levels, using a residual method similar to that of Hagos et al. (2010). The heating rate $Q$ is obtained as follows:

$$
Q=c_{p} \Pi\left[\frac{\partial \theta}{\partial t}+\nabla \cdot(\mathbf{v} \theta)-\theta(\nabla \cdot \mathbf{v})+\omega \frac{\partial \theta}{\partial p}\right],
$$

where $\theta$ is potential temperature, $p$ is pressure, $c_{p}$ the specific heat at constant pressure, $\mathbf{v}$ the horizontal velocity, $\omega=\partial p / \partial t$, and $\Pi=\left(p / p_{0}\right)^{R / c_{p}}$ is the Exner function, where $p_{0}=1000 \mathrm{hPa}$ and $R$ is the gas constant. The heating was vertically integrated over the following nine layers: 1000-925, 925-850, 850-775, 775-650, 650-550, 550-450, 450-350, 350-200, and 200-50 hPa. 

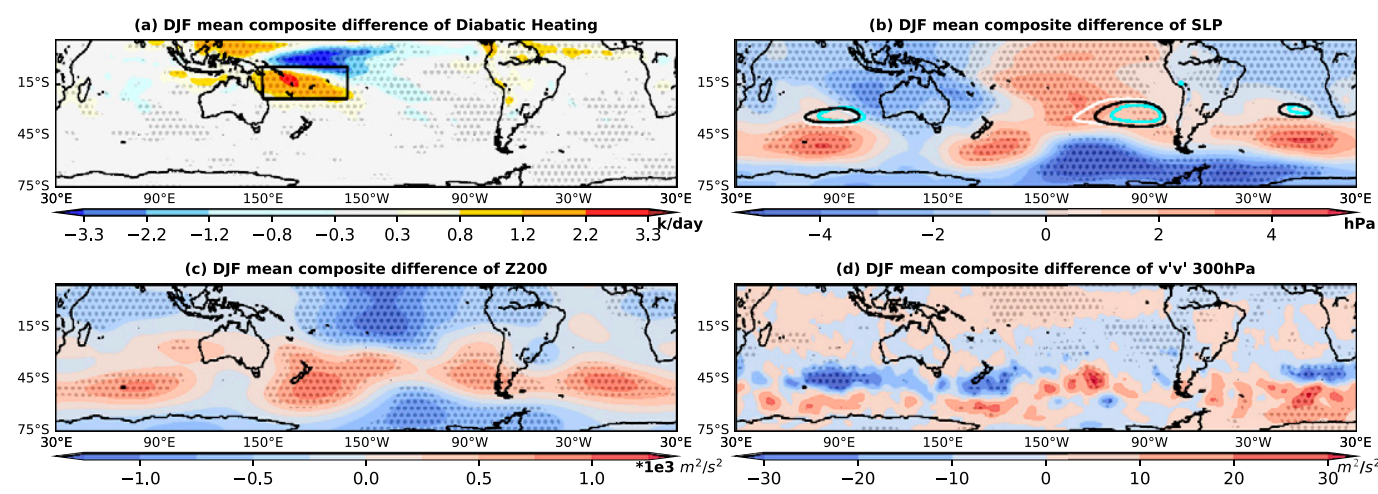

FIG. 3. The ERA-Interim DJF mean composite difference between maximum heating years and minimum heating years over the SPCZ region (shown as a black box) for (a) diabatic heating (unit: $\mathrm{K} \mathrm{day}^{-1}$ ), (b) SLP (unit: $\mathrm{hPa}$ ), (c) geopotential height at $200 \mathrm{hPa}$ (unit: $\mathrm{m}^{2} \mathrm{~s}^{-2}$ ), and (d) $V^{\prime} V^{\prime}$ at $300 \mathrm{hPa}\left(\mathrm{m}^{2} \mathrm{~s}^{-2}\right)$. The climatological 1020hPa contour (1979-2016) (black), mean 1020-hPa contour for the maximum heating years (white), and mean 1020$\mathrm{hPa}$ contour for the minimum heating years (blue) are shown in (b). The panels are stippled at $90 \%$ significance computed from the two-sided $t$-test difference of mean on the sampled years.

While our main focus is on the seasonal cycle of the SPSA a composite analysis is performed in order to demonstrate how interannual variability in DJF SPCZ heating influences the SH large-scale circulation and the SPSA. For the composite analysis, five maximum SPCZ heating years (maximum heating years) are compared with five minimum SPCZ heating years (minimum heating years) that are selected based on vertically integrated DJF SPCZ heating. The chosen domain of the SPCZ heating region is $24^{\circ}-5^{\circ} \mathrm{S}, 150^{\circ} \mathrm{E}-160^{\circ} \mathrm{W}$ (shown as a box in Fig. 3a). The maximum heating years in the composite are 1989, 1999, 2008, 2011, and 2012 and minimum heating years are 1992, 1993, 1995, 2003, and 2016 (DJF of these years refers to the December of that year and January-February of the following year). The ERA-Interim 1020-hPa isobar area and position are used to identify the SH SAs. The strength of the SPSA is calculated using domain-averaged SLP associated with the SPSA $\left(23^{\circ}-45^{\circ} \mathrm{S}, 80^{\circ}-130^{\circ} \mathrm{W}\right)$.

Based on the ERA-Interim composite analysis alone it is hard to isolate the SPCZ heating influence on SH large-scale circulation and the SAs. While the composite analysis helps to isolate the role of SPCZ heating within interannual variability, diabatic heating changes outside of the SPCZ region are still evident (Fig. 3a). In particular, there is evidence of an imprint from ENSO (Fig. 3a; see also Fig. S4), which is not surprising given associations between SPCZ variability and ENSO. The difference in SPCZ heating between the maximum and minimum heating years in DJF is $0.71 \mathrm{~K} \mathrm{day}^{-1}$ whereas the difference in SPCZ heating between DJF and JJA is $1.33 \mathrm{~K} \mathrm{day}^{-1}$. The DJF SPCZ heating difference between the maximum and minimum heating years is $53 \%$ of the seasonal cycle difference between DJF and JJA climatological SPCZ heating (Fig. S3).

To address this shortcoming and isolate the role of changes in SPCZ heating with magnitudes comparable to its seasonal cycle, sets of atmospheric general circulation model (AGCM) experiments with variable SPCZ heating rates are carried out using the Community Atmosphere Model version 6 (CAM6), with prescribed climatological SST. CAM6 is the atmospheric component of the Community Earth System Model version 2 (Danabasoglu et al. 2020). The CAM6 numerical experiments are done with a $1.9^{\circ} \times 2.5^{\circ}$ resolution and the F2000climo component set forced with prescribed ERA-Interim climatological SST (1979-2016). Under the F2000climo component set, radiative forcing and land surface boundary conditions are representative of conditions for the year 2000. The initial conditions used for the 30-yr continuous Control simulation are taken from a previously spun-up CESM simulation.

The AGCM experiments with variable SPCZ heating consist of two sets of idealized experiments. The first set incorporates artificially weakened austral summer SPCZ heating ("Added Cooling"); the second set artificially intensified heating ("Added Heating"). These two sets each consist of 30 simulations and their DJF seasonal mean is compared to the DJF climatology from a 30-yr-long control simulation. The control run is initialized using atmospheric initial conditions from a previously spun-up CESM simulation, forced with monthly climatological SST, and is run for 30 years. Subsequently, the seasonal runs are initialized 1 November as a branch run (from each 1 November of the control run) and run through to the following February with added cooling or heating applied to the SPCZ region. The Added Cooling and Added Heating experiments are both forced with prescribed SST, identical to the control run. Only DJF is considered for analysis (ignoring November, the first month of the Added Cooling and Added Heating experiments). The model's applied heating technique is similar to that of Swenson et al. (2019). The cooling and heating were added (in addition to all other diabatic heating processes naturally generated by the model) along with the DJF climatological position of the SPCZ with the maximum centered at $13^{\circ} \mathrm{S}, 170^{\circ} \mathrm{E}$ and a vertical peak at the 500-hPa level (Fig. 4). The horizontal and vertical structure of the added heating is shown in Fig. 4. A constant temperature tendency of $\pm 0.12 \mathrm{~K} \mathrm{day}^{-1}(15 \%$ of the total local climatological heating computed from the 30-yr DJF climatology of the control run) is applied to the Added Cooling and 



FIG. 4. (a) Zonal mean and (b) vertical mean added-heating structure of the Added Cooling experiments forcing file (units: $\mathrm{K} \mathrm{day}^{-1}$ ). The Added Heating experiments have the same addedheating structure, except the opposite sign.

Added Heating runs over the SPCZ region center starting from November, with Gaussian decay away from the maximum heating (but still within the SPCZ region; Fig. 4). The $15 \%$ applied heating acts as a seed within the model from which amplifying feedbacks within the model lead to more anomalous heating with the same sign (Swenson et al. 2019). The size of the imposed heating perturbation is selected to achieve a balance between maximizing the anomalous heating that results over the SPCZ region and minimizing any secondary responses over regions outside the SPCZ domain that can potentially influence atmospheric circulation if too strong.

This constant applied heating and cooling is very small compared to the DJF seasonal mean SPCZ heating in the Control run (the horizontal lines in Fig. 5a). However, amplifying feedbacks in the model leads to additional anomalous heating/cooling in the applied heating/cooling region (see Fig. 5a for the mean and spread in the net result). For example, the Control diabatic heating in the SPCZ region is $1.35 \mathrm{~K}_{\text {day }}{ }^{-1}$ in DJF and $0.53 \mathrm{~K} \mathrm{day}^{-1}$ in JJA (Fig. 5). In the Added Heating run $0.018 \mathrm{~K} \mathrm{day}^{-1}$ of heating is applied in the SPCZ region. However, due to the model creating its own anomalous heating over the SPCZ region, the 30-yr mean net diabatic heating in the DJF Added Heating experiments is $1.65 \mathrm{~K} \mathrm{day}^{-1}$ (Fig. 5). Similarly, in the Added Cooling experiments, $-0.018 \mathrm{~K} \mathrm{day}^{-1}$ of heating is applied, which then results in $0.97 \mathrm{~K} \mathrm{day}^{-1}$ ensemble-mean SPCZ heating during DJF due to model feedbacks. Therefore the local feedbacks within CAM6 act to amplify the small prescribed change in the heating. As a result, the pattern and magnitude of heating change over the SPCZ region are not directly opposite in nature between the Added Heating and Added Cooling experiments compared to the Control run.

The CESM2 CAM6 30-yr climatology shows similar SH seasonal characteristics to those in ERA-Interim (Figs. 1i,j). However, it overestimates the SLP over the subtropical regions compared to ERA-Interim, especially over the SPSA. To analyze a similar area of the SAs, the 1022-hPa isobar area is considered for the SASA and SISA, and the $1025-\mathrm{hPa}$ area is considered for the SPSA.

To understand the remote teleconnection between the SPCZ region and SH subtropical region, we used ray tracing of barotropic Rossby wave propagation in the upper troposphere (at $200 \mathrm{hPa}$ ) using the zonal wind, meridional wind, and streamfunction (Whitman 1974; Karoly 1983). The stationary Rossby wave (zero frequency) ray tracing is done following the general theory of ray tracing similar to Shaman and Tziperman (2005). The ray tracing is initiated over the SPCZ region with stationary zonal wavenumber $(k=5)$, and tracing was terminated after 15 days after the location is traced every $6 \mathrm{~h}$. The initial meridional wavenumber $(l)$ is calculated based on dispersion relation and initial ray tracing locations time-mean zonal and meridional wind (Karoly 1983; Shaman and Tziperman 2005).

To study the influence of SPCZ heating on the storm track position, transient eddy momentum velocity variance $U^{\prime} U^{\prime}$ and $V^{\prime} V^{\prime}$ at $300 \mathrm{hPa}$ are analyzed based on 6-hourly data. Here transients $\left(U^{\prime}, V^{\prime}\right)$ are defined as all components of $(U, V)$ with periods less than about 6 days, as obtained with a Butterworth filter. The strength of the upper-level storm track can be inferred from the transient eddy meridional velocity $\left(V^{\prime} V^{\prime}\right)$ at $300 \mathrm{hPa}$.

\section{Results}

\section{a. SPCZ heating in ERA-Interim}

The DJF composite difference between maximum heating years and minimum heating years shows a shift in heating from the equatorward flank of the SPCZ to the climatological position of the SPCZ (Fig. 3a). The composite difference based on the same years shows a positive-negative SLP anomaly pattern over the SH subtropical and midlatitude region, consistent with the signature of a Rossby wave train (Fig. 3b). The wave train forced by the intensified SPCZ heating propagates poleward, appears to reach a turning latitude, and then propagates equatorward (as in Hoskins and Karoly 1981). It is this equatorward-oriented branch that affects the SPSA. The wave train's positive SLP anomaly projects onto the SPSA, leading to an increase in its strength and area. For the minimum heating years, the area enclosed by the $1020-\mathrm{hPa}$ contour (shown in blue) of the SPSA decreases compared to the climatological area (black contour) (Fig. 3b). In contrast, the 1020-hPa area (white contour) increases and extends westward during maximum SPCZ heating years. Although positive/ negative SLP anomalies associated with the Rossby wave train are present over the South Atlantic and south Indian Ocean basins, significant changes (as indicated by the stippling 

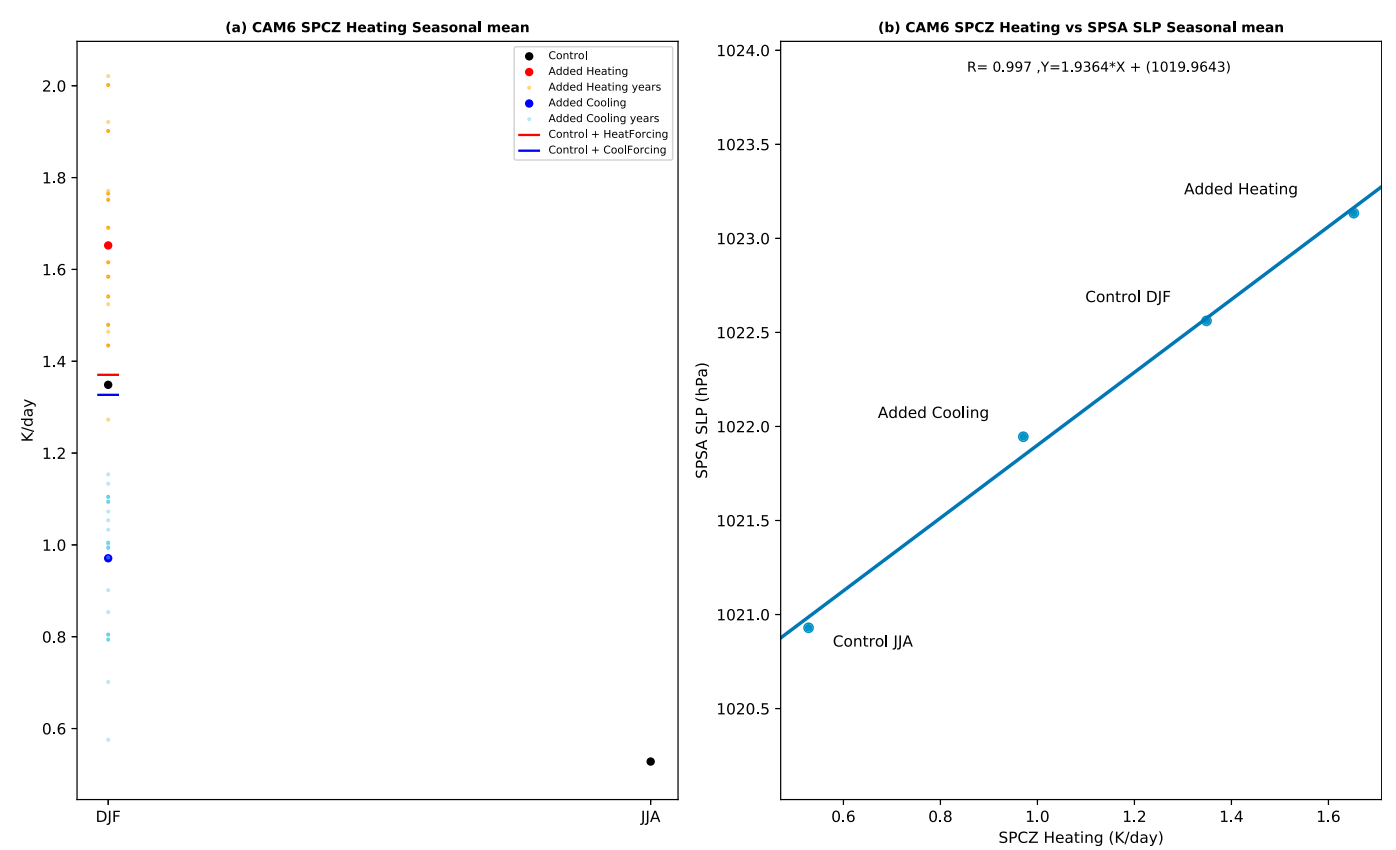

FIG. 5. DJF and JJA seasonal mean (a) SPCZ heating (unit: $\mathrm{K} \mathrm{day}^{-1}$ ) and (b) SPSA SLP (unit: hPa) of the CAM6 Control (black dot), Added Heating (red dot), and Added Cooling (blue dot) numerical experiments. (c) The scatterplot between seasonal mean SPCZ heating vs SPSA SLP along with a regression line $\left(R^{2}=0.994\right)$. The red and blue bars in (a) shows the sum of the DJF SPCZ heating in the Control run and the applied heating in the Added Heating and Added Cooling experiment, respectively. The red and blue dots show the resultant net heating due to the model's amplifying feedbacks.

in Fig. 3b) are seen only over the poleward flank of the SASA and the SISA. Therefore, there are no significant changes in the area and strength of the centers of the SASA and the SISA. The geopotential height at 200-hPa (Z200) composite difference between the maximum and minimum heating years shows qualitatively a similar response (Fig. 3c). A Z200 positive/ negative height change similar to the Rossby wave train response is noticeable over the $\mathrm{SH}$ midlatitude and subtropical regions. With increased heating over the SPCZ region, the Z200 height increases over the SPSA's center and poleward flank. There are however no significant Z200 height changes over the SASA and the SISA centers with the positive height changes in response to increases SPCZ heating confined to the poleward flanks of the SASA and the SISA.

The transient eddy variance $\left(V^{\prime} V^{\prime}\right)$ at $300 \mathrm{hPa}$ shows a physically consistent response due to a change in the SPCZ heating. The large belt of decreased SLP throughout the mid-to high-latitude $\mathrm{SH}$ shown in Fig. $3 \mathrm{~b}$ is accompanied by a poleward shift in the storm tracks at most longitudes. However, the low pressure area extending toward the SPSA in Fig. 3b (around $50^{\circ} \mathrm{S}, 120^{\circ} \mathrm{W}$ ) is accompanied by an increase in eddy variance, somewhat to the south and west of the SPSA.

As mentioned in the methods section (section 2), while this compositing approach helps to isolate the role of SPCZ heating within interannual SH SLP and storm track variability, it does not truly separate the role of the SPCZ from the influence of other modes of interannual variability. The response of SPSA SLP in the SPCZ heating versus cooling years compared to climatology is not linear with a larger SLP response in the cooling years (Fig. S3). As the response of the SPSA in these composites could be the result of other interannual modes of variability in addition to the anomalous SPCZ heating, further investigation is needed to isolate the influence of SPCZ heating on the SPSA. This motivates the analysis presented in the next section on the result from our prescribed SPCZ heating experiments.

\section{b. CAM6 numerical heating experiments}

The seasonal-mean, climatological, vertically integrated SPCZ diabatic heating in the CAM6 Control run is $1.35 \mathrm{~K} \mathrm{day}^{-1}$ in DJF and $0.53 \mathrm{~K} \mathrm{day}^{-1}$ in JJA (Fig. 5). The SPCZ heating decreases by $0.38 \mathrm{~K} \mathrm{day}^{-1}$ in the Added Cooling run compared to Control during DJF, which is $46 \%$ of the seasonal amplitude of SPCZ heating between DJF and JJA in the Control run (Fig. 5). The SPCZ heating increases by $0.30 \mathrm{Kday}^{-1}$ in the Added Heating run compared to Control, which is $37 \%$ of the seasonal amplitude of SPCZ heating between DJF and JJA in the Control run (Fig. 5). The SPCZ heating difference between Added Cooling and Added Heating is $0.68 \mathrm{~K} \mathrm{day}^{-1}$, which is $83 \%$ of the SPCZ heating difference between JJA and DJF seasonal mean in the control run. The domain average SLP change associated with the SPSA shows an approximately linear relation with the heating over the SPCZ region (Fig. 5b). In the Added Cooling experiments, the SPSA SLP per SPCZ heating change is $1.63 \mathrm{hPa} \mathrm{K}^{-1} \mathrm{day}^{-1}$, and in the Added Heating experiments the SPSA SLP per SPCZ heating change 

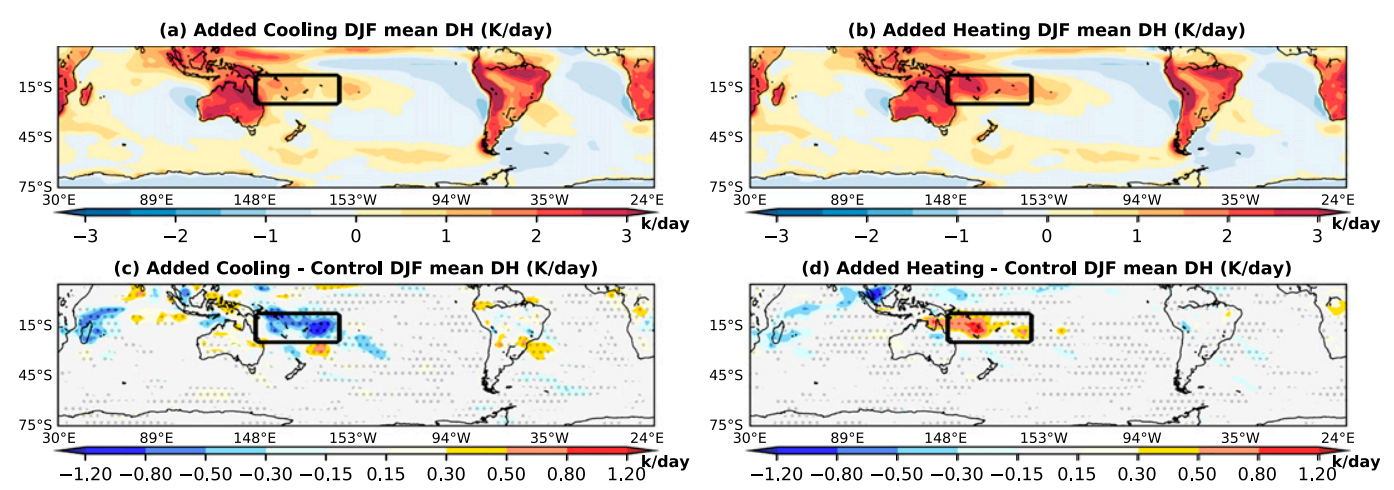
(e) Added Cooling DJF mean SLP (hPa)
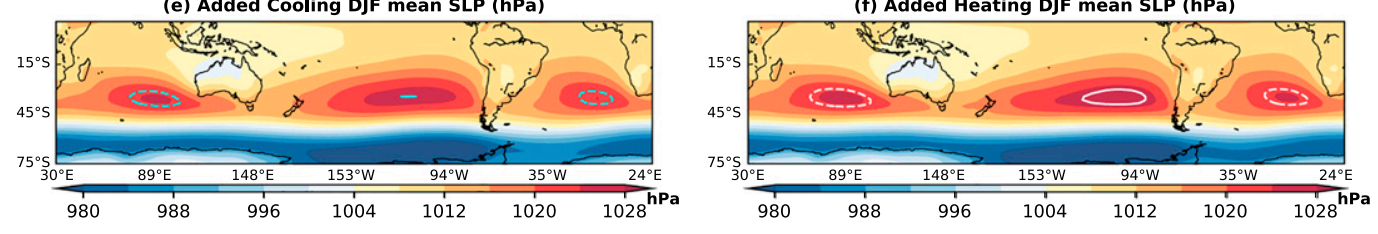

(g) Added Cooling - Control DJF mean SLP (hPa)

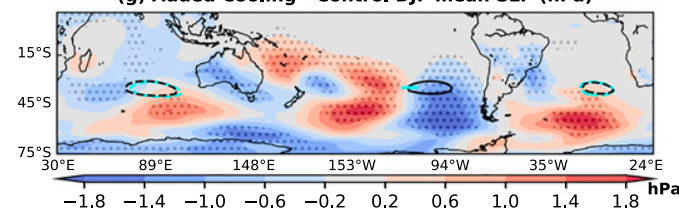

(h) Added Heating - Control DJF mean SLP (hPa)

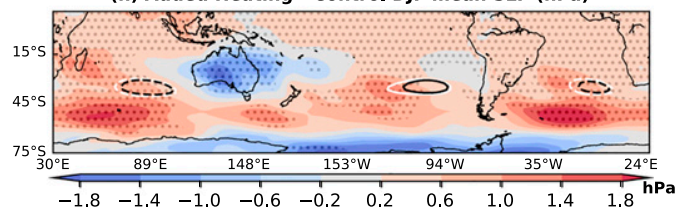

(i) Added Cooling - Added Heating DJF mean DH (K/day)
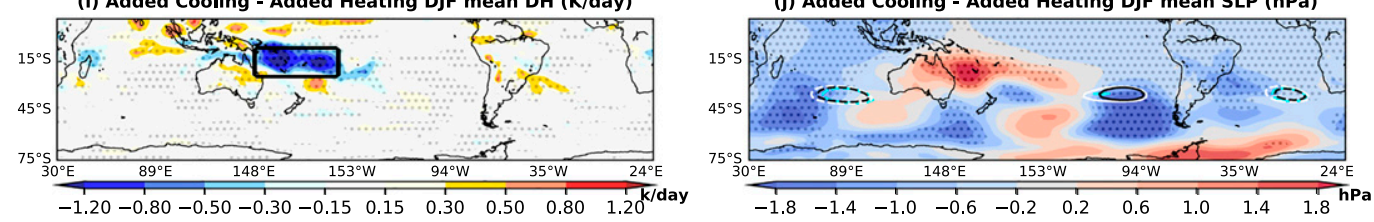

FIG. 6. The 30-yr DJF mean CESM2 CAM6 diabatic heating (unit: $\mathrm{K} \mathrm{day}^{-1}$ ) from (a) the Added Cooling runs, (b) the Added Heating runs, (c) the difference between the Added Cooling runs and the control run, and (d) the difference between the Added Heating runs and the Control run. The black box shows the SPCZ heating region where the temperature tendency was added. (e)-(h) As in (a)-(d), but for SLP (unit: hPa). The center of each SA in the Control run is contoured in black, the Added Cooling runs in blue, and the Added Heating runs in white. A solid contour shows the $1025-\mathrm{hPa}$ isobar, and a dotted contour shows the $1022-\mathrm{hPa}$ isobar. The difference between the Added Cooling and Added Heating experiments is shown for (i) diabatic heating and (j) SLP. The panels are stippled at $95 \%$ significance computed using a difference-of-means two-sided $t$ test.

is $1.9 \mathrm{hPa} \mathrm{K}^{-1}$ day $^{-1}$ compared to the Control run. This amounts to a very small nonlinearity in the response to SPCZ heating when evaluated using this particular metric for the strength of the SPSA, most likely arising from the different SPCZ heating patterns in the Added Cooling and Added Heating experiments (Fig. 5b). Results from CAM6 numerical experiments show that the SPCZ seasonal heating causes $88 \%$ of the seasonal enhancement of the SPSA (Fig. 5).

The DJF climatological mean SLP from the Added Cooling experiments shows significant changes in the $\mathrm{SH}$ subtropical and midlatitude atmospheric circulation compared to the control run (Figs. 6a,c,e,g). Due to a weakened SPCZ heating, a wave train of SLP anomaly pattern is generated over the SH subtropics (Figs. 6e,g). The negative SLP anomaly pattern over the Pacific Ocean projects onto the center of the SPSA in response to weakened SPCZ heating, consistent with the change found in the ERA-Interim composite analysis. In the Added Cooling experiments, the area of the SPSA center (1025-hPa contour) is very small. In contrast, in the Added Heating experiments, the size of the center of the SPSA increases and extends westward compared to the Control simulation (Figs. 6f,h). In contrast, the Added Heating over the SPCZ region increases the SPSA's area and strength by generating Rossby wave SLP train anomalies (Figs. 6,b,d,f,h). Interestingly, SLP changes at the center of the SPSA in the Added Cooling experiments (Fig. 6g) are significant at the $95 \%$ level, but not in the Added Heating experiments where the most significant changes occur to the west of its center (Fig. 6h). The extreme case scenario of Added Cooling - Added Heating experiments shows the weakened SPSAs strength due to decreased SPCZ heating during DJF (Figs. 6g,h). We again see in Figs. 6g,j a strong suggestion of a poleward propagating wave train which reaches a turning latitude and then propagates equatorward, influencing the SPSA. 

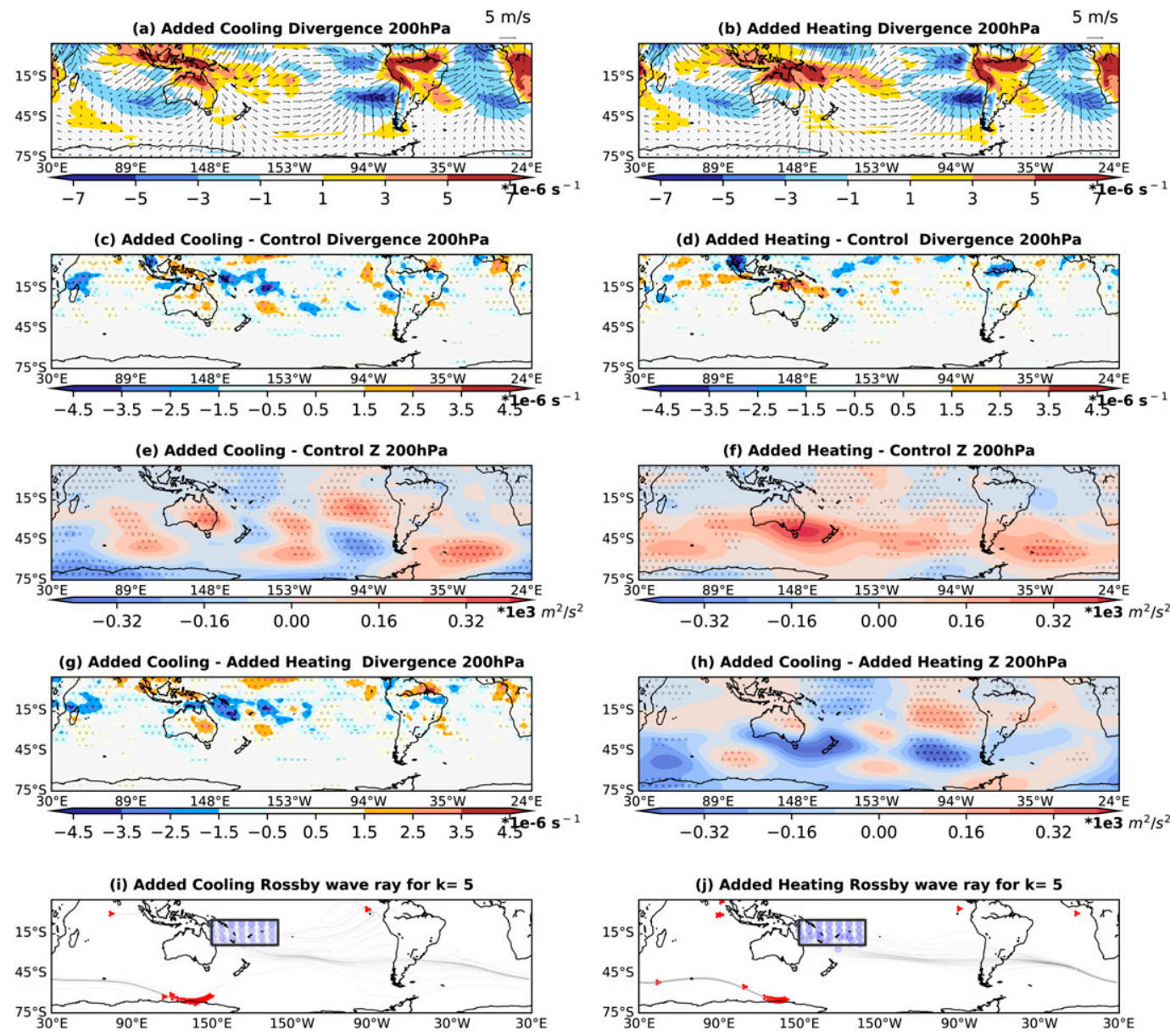

FIG. 7. The 30-yr DJF mean CESM2 CAM6 divergence at $200 \mathrm{hPa}$ (unit: $1 \times 10^{-6} \mathrm{~s}^{-1}$ ) for (a) the Added Cooling runs, (b) the Added Heating runs, (c) the difference between the Added Cooling run and the control run, and (d) the difference between the Added Heating runs and the control run. The 200-hPa wind divergence is plotted as vectors (unit: $\mathrm{m} \mathrm{s}^{-1}$ ). The geopotential height at $200 \mathrm{hPa}$ (unit: $1 \times 10^{3} \mathrm{~m}^{2} \mathrm{~s}^{-2}$ ) is shown for (e) the difference between the Added Cooling runs and the control run and (f) the difference between the Added Heating runs and the control run. The difference between the Added Cooling and Added Heating experiments is shown for (g) the divergence at $200 \mathrm{hPa}$ and $(\mathrm{h})$ the geopotential height at $200 \mathrm{hPa}$. The panels are stippled at $95 \%$ significance computed using a difference-of-means two-sided $t$ test. The Rossby wave ray traced from the SPCZ location is shown for stationary zonal wavenumber $k=5$ for (i) Added Cooling and (j) Added Heating experiments. The Rossby wave path is shown as gray lines, the initial location as blue circles, and the end of the ray as red dots.

Analysis of the 200-hPa divergence in these simulation shows that a decrease in heating over the SPCZ region leads to a decrease in divergence and divergent wind in the upper troposphere (Figs. 7a,c,g). The SPCZ heating change triggers a Rossby wave train over the SH subtropics and midlatitudes by changing the upper-level divergence and divergent wind. The SLP anomalies and Z200 height changes due to changes in the heating are consistent, again showing a stationary Rossby wave that propagates poleward and turns. In the cooling experiments, there is a decrease in Z200 height consistent with the decrease in SLP over the center and poleward flank of the SPSA (Fig. 7e). In contrast, the Z200 height increases over the center of SPSA due to increased upper-level divergence over the SPCZ region in the heating experiments (Figs. 7b,d,f).
The Z200 response is consistent with the extreme SPCZ heating change scenario (Figs. 7g,h).

The Rossby wave rays initialized from the SPCZ region show that the ray path matches the Rossby wave train visible in the 200-hPa geopotential height and SLP anomalies (Figs. 7i,j). The Rossby wave rays travel over the center of SPSA, then move toward the pole in the Atlantic and the Indian Ocean. The Rossby wave ray density initialized from the SPCZ region is a bit more scattered in the Added Cooling experiments compared to the Added Heating experiments. More Rossby wave rays travel toward the equator in the Added Cooling experiment, whereas Rossby wave rays are more densely propagating toward the center of the SPSA in the heating experiments (Figs. 7i,j). 

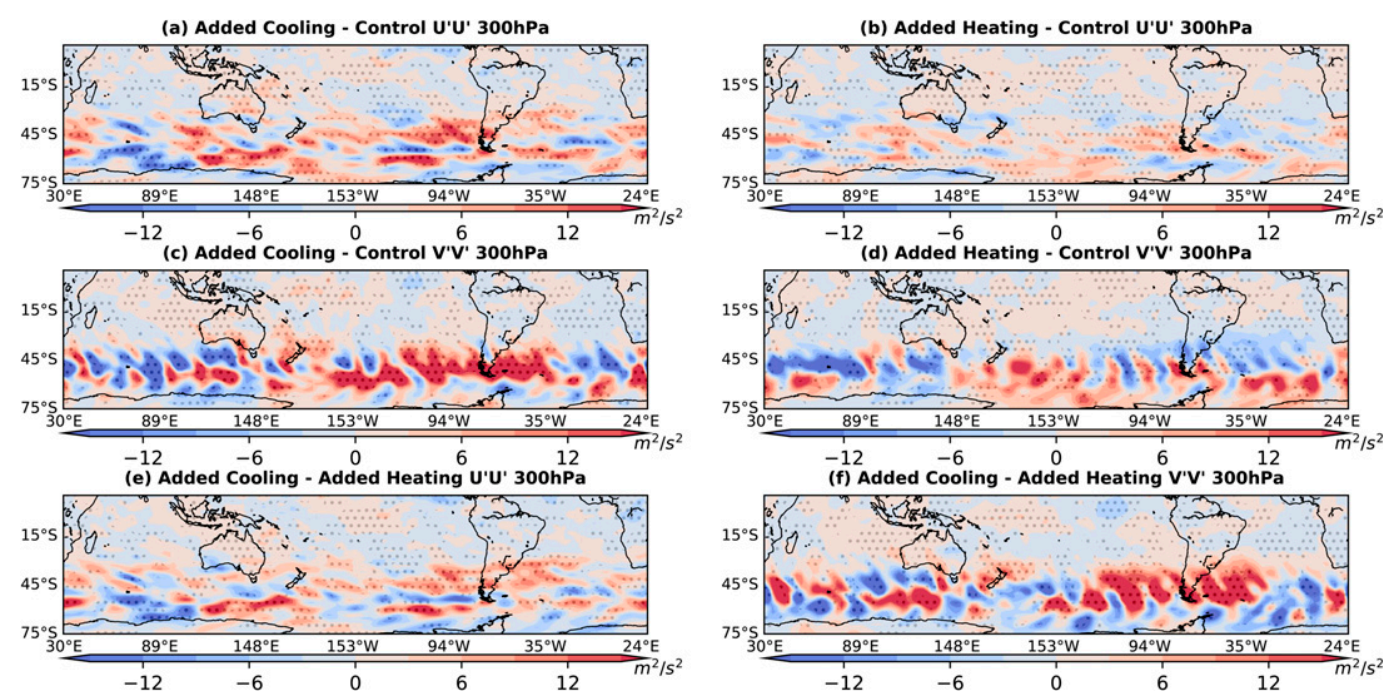

FIG. 8. The 30-yr DJF mean CESM2 CAM6 $U^{\prime} U^{\prime}$ at $300 \mathrm{hPa}\left(\right.$ unit: $\mathrm{m}^{2} \mathrm{~s}^{2}$ ) for (a) the difference between the Added Cooling runs and the control run and (b) the difference between the Added Heating runs and the control run. Also shown are $V^{\prime} V^{\prime}$ at $300 \mathrm{hPa}$ (unit: $\mathrm{m}^{2} \mathrm{~s}^{2}$ ) for (c) the difference between the Added Cooling runs and the control run and (d) the difference between the Added Heating runs and the control run, as well as the difference between the Added Cooling runs and the Added Heating runs is shown for (e) $U^{\prime} U^{\prime}$ at $300 \mathrm{hPa}$ and (f) $V^{\prime} V^{\prime}$ at $300 \mathrm{hPa}$. The panels are stippled at $95 \%$ significance computed using a difference-of-means two-sided $t$ test.

The SPCZ heating also significantly influences the SH storm track strength and position, which potentially amplifies the SPSA response to the SPCZ heating. The transient eddy zonal momentum flux $\left(U^{\prime} U^{\prime}\right)$ at $300 \mathrm{hPa}$ and transient eddy meridional momentum flux $\left(V^{\prime} V^{\prime}\right)$ at $300 \mathrm{hPa}$ show that the strength of the SH storminess increases over the South Pacific Ocean near the SPSA due to a decrease of the SPCZ heating (Figs. 8a,c). The storm track response seen in Fig. 8c is consistent with the wave train propagation seen in Fig. 7, leading to increased storminess in a region just south of the SPSA. The storminess increases over the eastern South Pacific region due to weakened SPCZ heating that potentially plays a secondary role to weaken the strength of the SPSA. The storm track response in the Added Heating experiments has a more ambiguous signature near the SPSA (Figs. 8b,d). However, when assessing the full Added Cooling minus Added Heating response the storm track shifts (Figs. 8e,f), showing a clear sign of the storm tracks influencing the SPSA.

\section{Conclusions and discussion}

In this study, the influence of austral summer SPCZ heating on subtropical atmospheric circulation in the $\mathrm{SH}$ is investigated through a composite analysis of interannual internal variability and a series of prescribed cooling/heating experiments. During austral summer (DJF), the center of the SPSA is stronger than in austral winter (JJA). This stands in contrast to the centers of the SASA and SISA, which reach their maximum in strength and area during austral winter (JJA). Previous studies have attributed these JJA maxima of the SH subtropical highs to enhanced NH monsoonal heating. The results of this study show that changes in the SPCZ heating, which reaches its seasonal maximum during DJF, lead to an enhancement of the area and strength of the center of the SPSA by generating a stationary Rossby wave that propagates poleward across the South Pacific into the SH midlatitudes, and then turns and propagates equatorward.

An $\mathrm{SH}$ midlatitude wave train of high and low pressure is consistent with increased heating over the SPCZ region during DJF in the ERA-Interim composite analysis. The positive SLP anomalies project onto the center of the SPSA, leading to an increase in area and strength. The Z200 height anomalies show a pattern of increased height consistent with an increased SLP anomaly.

The AGCM CAM6 is used to analyze the influence of weakened and strengthened SPCZ heating on SH atmospheric circulation. The Added Cooling and Added Heating prescribed SST experiments are compared with a Control run to investigate the influence of SPCZ heating during DJF. Results show a Rossby wave train of high and low pressure emanating from the SPCZ region and propagating poleward into the $\mathrm{SH}$ due to changes in upper-level divergence over the SPCZ in response to heating changes. The increased SPCZ heating anomalies force anomalous ascent leading to anomalous divergence aloft and hence perturbing the Rossby wave source term in the barotropic vorticity equation. The Rossby wave train response in the South Pacific Ocean basin occurs over the subtropical to midlatitude regions, whereas in the South Atlantic and the Indian Ocean regions the Rossby wave train response is only significant over the poleward flank of the SASA and the SISA. In contrast, weakened SPCZ heating leads to an opposite Rossby wave train response over the $\mathrm{SH}$ subtropics and midlatitudes that weakens the SPSA's area and strength. However, there are no significant SLP changes over 
the subtropics of the south Indian and South Atlantic Oceans, except on the poleward flanks. It is noteworthy that the Added Cooling experiments show a much cleaner Rossby wave response (compared to the Control) than do the Added Heating experiments.

The 200-hPa geopotential height also shows a height increase over the SPSA in response to increased heating over the SPCZ region and the opposite response due to cooling over the SPCZ region. The Rossby wave ray tracing initialized from the SPCZ region shows the density of Rossby wave rays traveling toward the center of the SPSA increases with increases SPCZ heating. The Rossby wave rays are scattered and travel toward the equator more in the Added Cooling experiment compared to the Added Heating experiment. The traced wave ray path is also consistent with the SH subtropical Z200 and SLP changes in the Added Cooling and Added Heating experiment compared to the Control run.

The pattern of SLP and Z200 changes in the SH associated with changes in the SPCZ heating are broadly consistent between the ERA-Interim composite analysis and the CAM6 heating experiments. In the CAM6 runs, forced equatorial heating changes are also visible outside the SPCZ region (e.g., over the Maritime Continent) due to changes in heating over the SPCZ region (Figs. 6c,d). However, they are much smaller in size and magnitude compared to the SPCZ heating changes, and likely play a secondary role at best. There is also an opposite response of SLP and Z200 noticeable between the CAM6 Added Heating runs and ERA-Interim (e.g., poleward of $45^{\circ} \mathrm{S}$ at around $90^{\circ} \mathrm{W}$ ) (Figs. 3 and 6). This could be due to the influence of other modes of the interannual variability (e.g., southern annular mode, local SST) in the ERA-Interim composite analysis.

The heating over the SPCZ region also significantly influences the strength and position of the SH storm tracks during austral summer (DJF). The SH storm track is shifted poleward due to the increased SPCZ heating in both ERA-Interim and CAM6. The baroclinic eddy growth and strength of storminess decreases where the SLP associated with the Rossby wave train has positive anomalies due to change in the SPCZ heating. In contrast, weakened SPCZ heating leads to increased seasonal mean storminess over the equatorward $\mathrm{SH}$ storm tracks.

The results show that Rossby waves triggered by SPCZ heating do not influence the SASA and SISA during DJF. There are two other convergence zones present over the South Atlantic and Indian Oceans during DJF; they are however weaker than the SPCZ. The convergence of the South Atlantic is reported to be influential to the weather and climate of South America (Barros et al. 2000), and similarly South Indian convergence zone to southern Africa (Barimalala et al. 2018). Further studies are needed to understand the relation between the strength of these convergence zones and the SASA and SISA, respectively.

Although the seasonal cycle of the SH SAs in the CAM6 runs is similar compared to ERA-Interim, the area and strength of the SAs are overestimated by CAM6 $(\sim 7-10 \mathrm{hPa})$ (Fig. 1). A similar bias in the seasonal cycle of SA is also present in the coupled CESM2 model used in CMIP6 as well as the earlier CCSM4/CESM1 version used in CMIP5 (Fahad et al. 2020). The bias in the SAs in CAM6 during both seasons could be due to intensified local land-sea diabatic heating differences, overestimating tropical diabatic heating, or both. Future work will focus on the role of climatological biases in diabatic heating in the development of the climatological biases seen in the strength and seasonal cycle of the SH SAs and midlatitude atmospheric circulation in CAM6 prescribed SST and coupled CESM2 historical simulations.

The interannual variability in the SPCZ during austral summer is closely related to the ENSO modes and MJO as discussed in the introduction. Further study is needed to understand how ENSO and MJO can potentially influence the location and magnitude of SPCZ heating and hence influence the variability of SPSA on the interannual time scale.

Acknowledgments. This study was supported by the National Science Foundation (NSF; AGS-1613318, AGS-1338427), the National Aeronautics and Space Administration (NASA; NNX14AM19G), and the National Oceanic and Atmospheric Administration (NOAA; NA14OAR4310160). N.J.B. is supported by the Alfred P. Sloan Foundation as a Research Fellow. We acknowledge high-performance computing and analysis support from Cheyenne (https://doi.org/10.5065/D6RX99HX) provided by NCAR's Computational and Information Systems Laboratory, sponsored by the NSF. We also acknowledge ECMWF for use of the ERA-Interim dataset downloaded from https:/www.ecmwf.int/en/forecasts/datasets/reanalysis-datasets/ era-interim.

\section{REFERENCES}

Allan, R., and T. Ansell, 2006: A new globally complete monthly historical gridded mean sea level pressure dataset (HadSLP2): 1850-2004. J. Climate, 19, 5816-5842, https://doi.org/10.1175/ JCLI3937.1.

Barimalala, R., F. Desbiolles, R. C. Blamey, and C. Reason, 2018: Madagascar influence on the South Indian Ocean convergence zone, the Mozambique Channel Trough and southern African rainfall. Geophys. Res. Lett., 45, 11 380-11389, https://doi.org/ 10.1029/2018GL079964.

Barros, V., M. Gonzalez, B. Liebmann, and I. Camilloni, 2000: Influence of the South Atlantic convergence zone and South Atlantic sea surface temperature on interannual summer rainfall variability in southeastern South America. Theor. Appl. Climatol., 67, 123-133, https://doi.org/10.1007/s007040070002.

Bergeron, T., 1930: Richlinien einer dynamischen Klimatologie. Meteor. Z., 47, 246-262.

Brown, J. R., and Coauthors, 2020: South Pacific Convergence Zone dynamics, variability and impacts in a changing climate. Nat. Rev. Earth Environ., 1, 530-543, https://doi.org/10.1038/ s43017-020-0078-2.

Burls, N. J., R. C. Blamey, B. A. Cash, E. T. Swenson, A. A. Fahad, M.-J. M. Bopape, D. M. Straus, and C. J. C. Reason, 2019: The Cape Town "Day Zero" drought and Hadley cell expansion. npj Climate Atmos. Sci., 2, 27, https://doi.org/10.1038/S41612019-0084-6.

Chen, P., M. P. Hoerling, and R. M. Dole, 2001: The origin of subtropical anticyclones. J. Atmos. Sci., 58, 1827-1835, https:// doi.org/10.1175/1520-0469(2001)058<1827:TOOTSA $>2.0 . C O ; 2$.

Clem, K. R., and J. A. Renwick, 2015: Austral spring Southern Hemisphere circulation and temperature changes and links to 
the SPCZ. J. Climate, 28, 7371-7384, https://doi.org/10.1175/ JCLI-D-15-0125.1.

Danabasoglu, G., and Coauthors, 2020: The Community Earth System Model version 2 (CESM2). J. Adv. Model. Earth Syst., 12, e2019MS001916, https://doi.org/10.1029/2019MS001916.

Dee, D. P., and Coauthors, 2011: The ERA-Interim reanalysis: Configuration and performance of the data assimilation system. Quart. J. Roy. Meteor. Soc., 137, 553-597, https://doi.org/ 10.1002/qj.828.

Doyle, M. E., and V. R. Barros, 2002: Midsummer low-level circulation and precipitation in subtropical South America and related sea surface temperature anomalies in the South Atlantic. J. Climate, 15, 3394-3410, https://doi.org/10.1175/ 1520-0442(2002)015<3394:MLLCAP>2.0.CO;2.

Fahad, A. A., N. J. Burls, and Z. Strasberg, 2020: How will Southern Hemisphere subtropical anticyclones respond to global warming? Mechanisms and seasonality in CMIP5 and CMIP6 model projections. Climate Dyn., 55, 703-718, https:// doi.org/10.1007/s00382-020-05290-7.

Folland, C. K., J. A. Renwick, M. J. Salinger, and A. B. Mullan, 2002: Relative influences of the interdecadal Pacific oscillation and ENSO on the South Pacific convergence zone. Geophys. Res. Lett., 29, 1643, https://doi.org/10.1029/2001GL014201.

Gelaro, R., and Coauthors, 2017: The Modern-Era Retrospective Analysis for Research and Applications, version 2 (MERRA-2). J. Climate, 30, 5419-5454, https://doi.org/10.1175/JCLI-D-16-0758.1.

Hagos, S., and Coauthors, 2010: Estimates of tropical diabatic heating profiles: Commonalities and uncertainties. J. Climate, 23, 542-558, https://doi.org/10.1175/2009JCLI3025.1.

Held, I. M., S. W. Lyons, and S. Nigam, 1989: Transients and the extratropical response to El Niño. J. Atmos. Sci., 46, 163-174, https://doi.org/10.1175/1520-0469(1989)046<0163:TATERT> 2.0.CO;2.

Holton, J., and G. J. Hakim, 2012: An Introduction to Dynamic Meteorology. 5th ed. Academic Press, 552 pp.

Hoskins, B. J., 1996: On the existence and strength of the summer subtropical anticyclones. Bull. Amer. Meteor. Soc., 77, 1287-1292.

_ spherical atmosphere to thermal and orographic forcing. J. Atmos. Sci., 38, 1179-1196, https://doi.org/10.1175/15200469(1981)038<1179:TSLROA > 2.0.CO;2.

Karoly, D. J., 1983: Rossby wave propagation in a barotropic atmosphere. Dyn. Atmos. Oceans, 7, 111-125, https://doi.org/ 10.1016/0377-0265(83)90013-1.

Lee, S. K., C. R. Mechoso, C. Wang, and J. D. Neelin, 2013: Interhemispheric influence of the northern summer monsoons on southern subtropical anticyclones. J. Climate, 26, 10193 10 204, https://doi.org/10.1175/JCLI-D-13-00106.1.

Lintner, B. R., and W. R. Boos, 2019: Using atmospheric energy transport to quantitatively constrain South Pacific convergence zone shifts during ENSO. J. Climate, 32, 1839-1855, https://doi.org/10.1175/JCLI-D-18-0151.1.

Liu, Y., G. Wu, and R. Ren, 2004: Relationship between the subtropical anticyclone and diabatic heating. J. Climate, 17, 682-698, https:// doi.org/10.1175/1520-0442(2004)017<0682:RBTSAA>2.0.CO;2.

Matthews, A. J., 2012: A multiscale framework for the origin and variability of the South Pacific Convergence Zone. Quart. J. Roy. Meteor. Soc., 138, 1165-1178, https://doi.org/10.1002/qj.1870.

Nigam, S., and S. C. Chan, 2009: On the summertime strengthening of the Northern Hemisphere Pacific sea level pressure anticyclone. J. Climate, 22, 1174-1192, https://doi.org/10.1175/2008JCLI2322.1.

Reboita, M. S., M. A. Gan, R. P. da Rocha, and T. Ambrizzi, 2010: Precipitation regimes in South America: A bibliography re- view. Rev. Bras. Meteor., 25, 185-204, https://doi.org/10.1590/ S0102-77862010000200004.

Renwick, J. A., and M. J. Revell, 1999: Blocking over the South Pacific and Rossby wave propagation. Mon. Wea. Rev., 127, 2233-2247, https://doi.org/10.1175/1520-0493(1999)127<2233: BOTSPA $>2.0 . \mathrm{CO} ; 2$.

Richter, I., C. R. Mechoso, and A. W. Robertson, 2008: What determines the position and intensity of the South Atlantic anticyclone in austral winter?-An AGCM study. J. Climate, 21, 214-229, https://doi.org/10.1175/2007JCLI1802.1.

, S. K. Behera, Y. Masumoto, B. Taguchi, N. Komori, and T. Yamagata, 2010: On the triggering of Benguela Niños: Remote equatorial versus local influences. Geophys. Res. Lett., 37, L20604, https://doi.org/10.1029/2010GL044461.

Rodwell, M. J., and B. J. Hoskins, 2001: Subtropical anticyclones and summer monsoons. J. Climate, 14, 3192-3211, https:// doi.org/10.1175/1520-0442(2001)014<3192:SAASM>2.0.CO;2.

Seager, R., R. Murtugudde, N. Naik, A. Clement, N. Gordon, and J. Miller, 2003: Air-sea interaction and the seasonal cycle of the subtropical anticyclones. J. Climate, 16, 1948-1966, https://doi.org/ 10.1175/1520-0442(2003)016<1948:AIATSC>2.0.CO;2.

Shaman, J., and E. Tziperman, 2005: The effect of ENSO on Tibetan Plateau snow depth: A stationary wave teleconnection mechanism and implications for the South Asian monsoons. J. Climate, 18, 2067-2079, https://doi.org/10.1175/JCLI3391.1.

Song, F., L. R. Leung, J. Lu, and L. Dong, 2018a: Seasonally dependent responses of subtropical highs and tropical rainfall to anthropogenic warming. Nat. Climate Change, 8, 787-792, https://doi.org/10.1038/s41558-018-0244-4.

,,$-- \ldots$, and $-2018 \mathrm{~b}$ : Future changes in seasonality of the North Pacific and North Atlantic subtropical highs. Geophys. Res. Lett., 45, 11 959-11 968, https://doi.org/10.1029/ 2018 GL079940.

Sturman, A. P., and N. J. Tapper, 1996: The Weather and Climate of Australia and New Zealand. Oxford University Press, 476 pp.

Sun, X., K. H. Cook, and E. K. Vizy, 2017: The South Atlantic subtropical high: Climatology and interannual variability. J. Climate, 30, 3279-3296, https://doi.org/10.1175/JCLI-D-16-0705.1.

Swenson, E. T., D. M. Straus, C. E. Snide, and A. A. Fahad, 2019: The role of tropical heating and internal variability in the California response to the 2015/16 ENSO event. J. Atmos. Sci., 76, 3115-3128, https://doi.org/10.1175/JAS-D-19-0064.1.

Taschetto, A. S., R. J. Haarsma, A. Sen Gupta, C. C. Ummenhofer, K. J. Hill, and M. H. England, 2010: Australian monsoon variability driven by a Gill-Matsuno-type response to central west Pacific warming. J. Climate, 23, 4717-4736, https:// doi.org/10.1175/2010JCLI3474.1.

Ting, M., 1994: Maintenance of northern summer stationary waves in a GCM. J. Atmos. Sci., 51, 3286-3308, https://doi.org/ 10.1175/1520-0469(1994)051<3286:MONSSW>2.0.CO;2.

Trenberth, K. E., 1976: Spatial and temporal variations of the Southern Oscillation. Quart. J. Roy. Meteor. Soc., 102, 639653, https://doi.org/10.1002/qj.49710243310.

Vizy, E. K., and K. H. Cook, 2016: Understanding long-term (19822013) multi-decadal change in the equatorial and subtropical South Atlantic climate. Climate Dyn., 46, 2087-2113, https:// doi.org/10.1007/s00382-015-2691-1.

Whitman, G. B., 1974: Linear and nonlinear waves. Scholarpedia, 4, 4308, https://doi.org/10.4249/scholarpedia.4308.

Wu, G., and Y. Liu, 2003: Summertime quadruplet heating pattern in the subtropics and the associated atmospheric circulation. Geophys. Res. Lett., 30, 1201, https://doi.org/ 10.1029/2002GL016209. 